\title{
The effect of blade slots on flow behaviour in a fan impeller
}

\author{
Adam Pieruszka ${ }^{1}$, Tomasz Siwek ${ }^{1 *}$, Wojciech Kalawa ${ }^{1}$, Lukasz Lis ${ }^{1}$, Sebastian Stefański ${ }^{1}$, Karol Sztekler ${ }^{1}$ \\ ${ }^{1}$ AGH University of Science and Technology Krakow, Faculty of Fuels and Energy, Department of thermal and fluid flow machines, \\ Poland
}

\begin{abstract}
The use of blade slots is one of the passive methods of controlling flow in a fan impeller. Numerical CFD analyses indicate a possibility of controlling the point of flow separation in the inter-blade space depending on various configurations of the aperture arrangement. Bench studies confirm the possibility of changing the increase of total pressure and internal efficiency. Additionally, the changes affect the noise level during fan operation..
\end{abstract}

\section{Submitting the manuscript}

An important aspect taken into account when considering flow control options in rotodynamic machines should be the boundary layer separation phenomenon. In fan designs it can occur in many places, above all in the diffusion areas which are characterised by a positive liquid pressure gradient within the boundary layer. The point of separation defines the location where this phenomenon begins. Then, the following flow conditions are satisfied:

$$
\begin{gathered}
v_{x}=0 \\
\left(\frac{\partial v_{x}}{\partial y}\right)_{y=0}=0
\end{gathered}
$$

The first of them is the general criterion for the occurrence of a boundary layer according to the Prandtl model [1] in which the kinetic energy at the point of contact between the medium with the surface is equal to zero. The second requirement indicates a change in the flow direction, which results in the occurrence of flow separation.

For many years scientists and designers around the world have been analysing flow control options in different fields of engineering. The main objective, depending on the scope of the research, is typically to increase or decrease the lift and drag, reduce vibrations and noise, or to improve the overall efficiency of a machine. A considerable portion of the studies concerns the aviation industry and the methods of reducing the adverse effect of the occurrence of separations on aerofoil surfaces and other elements of airships. A number of studies are also being conducted in the field of rotodynamic machines [2] and [3]. Flow control can be achieved by means of active and passive methods, both for laminar flow and turbulent flow [4]. The first group comprises technologies employing additional external energy apart from the flow. This will include techniques based on partial suction of the boundary layer, generation of micro vortices or surface vibrations, use of acoustic waves or plasma inductors. The passive methods do not require any additional external energy for operation. This group comprises the techniques of appropriate cross-section modelling, using slots, perforated surfaces or static micro vortex generators.

In rotodynamic machines, most analyses are performed using the passive methods due to the presence of moving elements. The purpose of the investigation by the German scientists Schnerr and Wursthorn [5] was to present the options for preventing cavitation in centrifugal pumps at low rotational speeds. One of them was the use of slots in impeller blades. The results of 2D numerical computations demonstrated that in the range of performance being investigated this is the most effective method of preventing occurrence of cavitation caused by loss of pressure. The prospect of utilising slots in the blades of centrifugal blowers was the subject of the investigation by Kassim, Saleh and Kadhum [6]. The results of the numerical and experimental investigations proved the positive effect of reducing pressure fluctuations during operation at sub-nominal flow rates. Karanth and Sharma [7], in turn, presented numerical studies concerning the options of using slots in a fan with a radial impeller and a diffuser part. The slots were characterised by a converging configuration towards the suction side of the blade and a radial arrangement. A two-dimensional analysis showed that in the given model the location of the slots has a significant effect on the flow formation and the optimal location was at $25 \%$ radial distance from the trailing edge of the impeller blade.

\section{Numerical (CFD) analyses}

Computational Fluid Dynamics (CFD) numerical methods were used in order to examine the effect of

\footnotetext{
* Corresponding author: siwek@agh.edu.pl
} 
blade slots on impeller flow behaviour. A unit from the WWOax fan assortment range was selected as the geometrical model as well as a segment of the supply tube and a spiral casing. The analysis was conducted based on the ANSYS software within the framework of the service 'RoMa-CFD for Rotodynamic Machines and the supercomputer network PL-Grid. The computational grid had approx. 4 million elements and 1.4 million nodes. The simulations were carried out for variable mass flow in the range from $0.02 \mathrm{~m}^{3} / \mathrm{s}$ to $0.77 \mathrm{~m}^{3} / \mathrm{s}$. Figure 1 presents the flow separation phenomenon in below-optimal and above-optimal operation points. Due to the flat shape of the blade, in over-nominal flows it occurs already in the region of the leading edge.

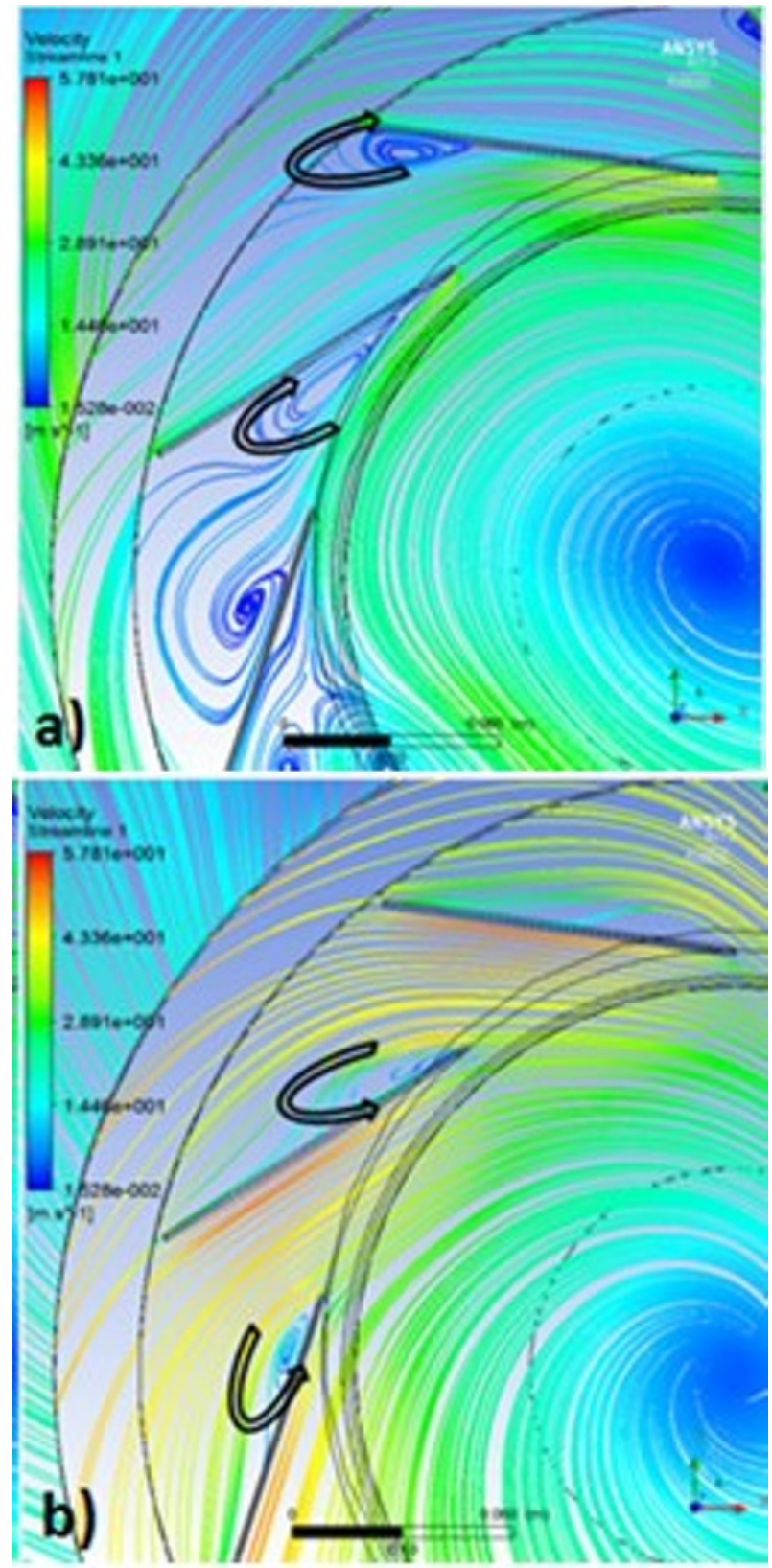

Fig. 1. Flow deflection at the operation point a) below-optimal and b) above-optimal

It was proposed to use blade slots made in the direction perpendicular to the blade surface with a constant aperture diameter along its length. The proposed configurations of slot locations and their dimensions are presented in Figure 2 and Table 1.

Table 1. Parameters of slot locations on a blade

\begin{tabular}{|c|c|c|c|c|c|c|c|}
\hline \multicolumn{2}{|c|}{ Designation } & W1 & W2 & W3 & W4 & W5 & W6 \\
\hline $\begin{array}{c}\text { Aperture } \\
\text { diameter }\end{array}$ & $\begin{array}{c}\mathrm{D} \\
{[\mathrm{mm}]}\end{array}$ & - & 1 & 2 & 1 & 1 & 1 \\
\hline $\begin{array}{c}\text { Distance } \\
\text { of the } \\
\text { first } \\
\text { aperture } \\
\text { from the } \\
\text { hub edge }\end{array}$ & $\begin{array}{c}\mathrm{L} 1 \\
{[\mathrm{~mm}]}\end{array}$ & - & 6 & 6 & 6 & 6 & 6 \\
\hline $\begin{array}{c}\text { Distance } \\
\text { from the } \\
\text { leading } \\
\text { edge }\end{array}$ & $\begin{array}{c}\mathrm{L} 2 \\
{[\mathrm{~mm}]}\end{array}$ & - & 30 & 20 & 20 & 10 & 20 \\
\hline $\begin{array}{c}\text { Spaces } \\
\text { between } \\
\text { the } \\
\text { apertures }\end{array}$ & $\mathrm{L} 3$ & - & 10 & 10 & 5 & 10 & 10 \\
\hline $\begin{array}{c}\text { Number } \\
\text { of } \\
\text { apertures }\end{array}$ & $\mathrm{i}$ & - & 6 & 6 & 13 & 6 & 6 \\
\hline
\end{tabular}

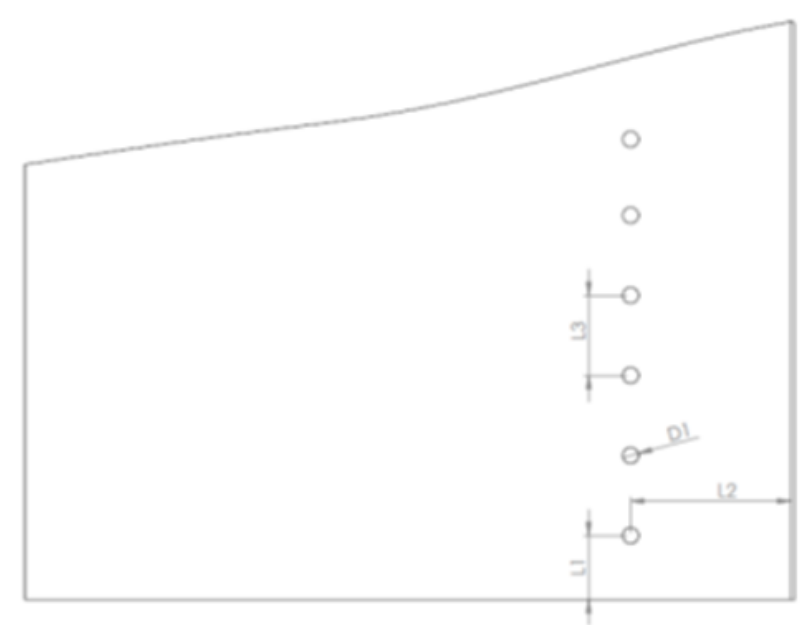

Fig. 2. Blade geometry with the designations

The parameters observed during the numerical computations were the total increase of pressure and internal efficiency. Due to small differences between these variables, Figures 3 and 4 present their relative values defined as the differences between the slot configuration being analysed (W2-W6) and the reference case (W1). The below graphs only include results for flows from $0.43 \mathrm{~m}^{3} / \mathrm{s}$ to $0.77 \mathrm{~m}^{3} / \mathrm{s}$. 


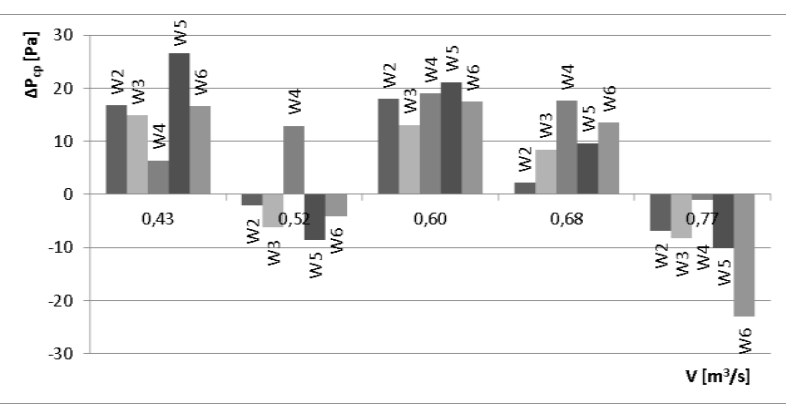

Fig. 3. Relative change in total pressure

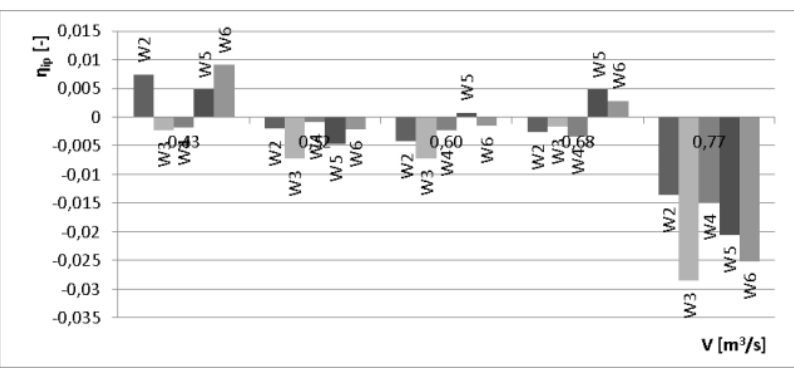

Fig. 4. Relative change in internal efficiency

Based on the results of the numerical analyses, one configuration of blade slots was selected, i.e. W5. The selection criteria were the relative change in internal efficiency, the change in total pressure and visualisation of the effect of the slots on flow formation in different cross-sections of the impeller.

\section{Test stand}

Validation of the numerical model requires carrying out bench tests. In order to determine flow characteristics, a test bench was prepared in compliance with PN-EN ISO 5801:2012. The type $\mathrm{C}$ test bench layout is shown in Figure 5.

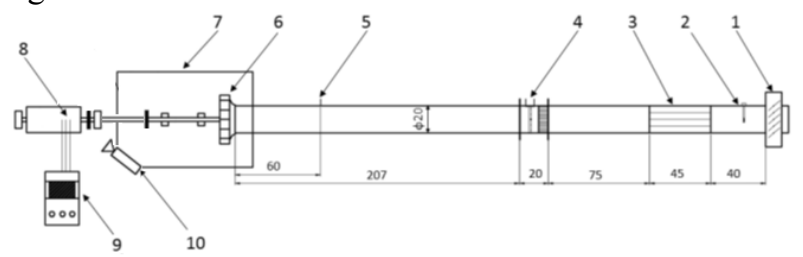

Fig. 5. Test bench for fan balance testing at the AGH Chair of Heat Engines and Turbomachines

At the tube inlet, a louvre damper (1) controlled by means of a stepper motor was mounted as well as a Delt Ohm HD48T thermohygrometer (2). Number (3) denotes a flow straightener the task of which is to normalise the velocity profile. By means of the STRA Dwyer measuring set (4) and a Halstup Walcher P26 differential pressure transmitter, flow rate measurements were made. Pressure at the suction side was determined by means of a Voltcraft VPT-100 anemometer (5). The other elements of the test bench are an impeller (6), a spiral casing (7), a three-phase electric motor (8), an inverter (9) and a digital tachometer Sentry ST723 (10). The air properties were determined by means of a digital thermo-hydro-barometer Comet D4130, while electrical measurements were made with a Fluke 1736 Power Logger.

Flow tests studies were carried out for the system with the reference impeller and with an impeller with selected blade slots (W5).

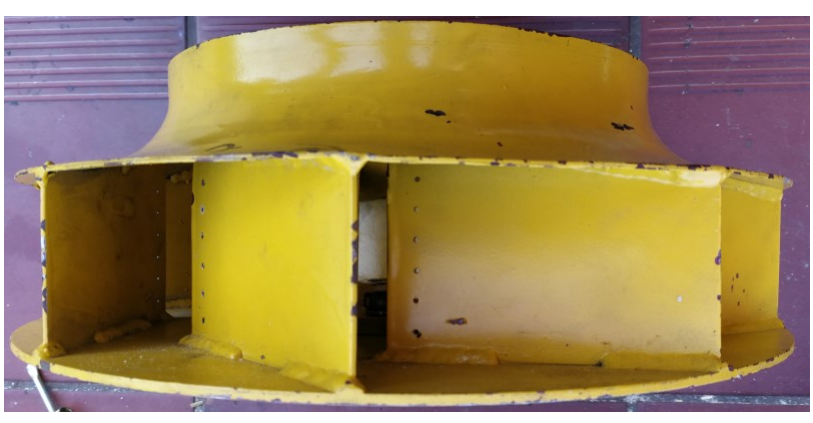

Fig. 6. Radial fan impeller with slots

\section{Results of the measurements and computations}

Based on the bench tests, flow characteristics were determined for the fan operation.

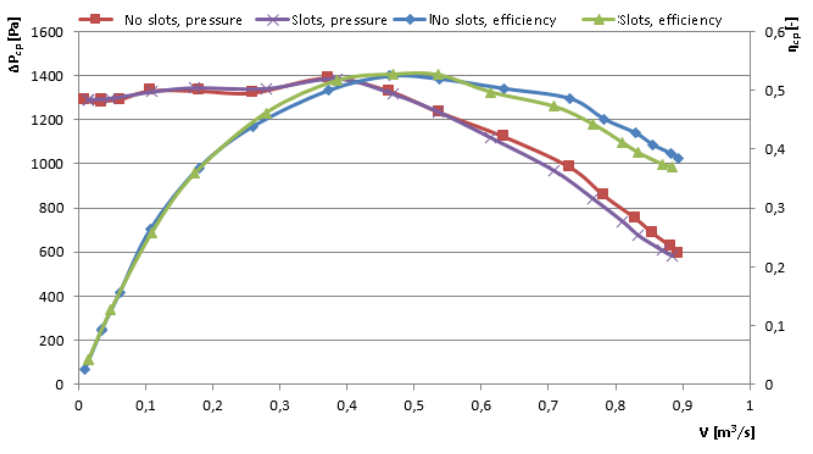

Fig. 7. Fan flow characteristics

Figure 7 presents the increase in total pressure and total internal efficiency for the system with the reference impeller and one equipped with blade slots. For the above-optimal flow values, an efficiency drop can be observed as well as a reduction in the total pressure generated. This is caused by the insignificant effect of the slots on separations, which occur in the region of the leading edge of the blade. For below-optimal flows, an increase can be observed in efficiency as well as in the total pressure value.

\section{Fan noise}

An important aspect of fan operation is its noise level. The measurement of the acoustic characteristic was made in compliance with PN-72/M-43120. The testing included measurement of sound levels with a meter equipped with correction filters $\mathrm{A}$ and $\mathrm{C}$ and taking samples with a ZOOM H2n recorder. In accordance with the standard, the tests were performed at four points around the fan outlet. Then, the measurements were 
averaged. Figure 8 presents the difference between the sound levels determined for the impeller with slots and the reference one. The difference in the shape of the characteristics may be caused by the operating principle of the correction filters. Type-A analyser corresponds to the frequency sensitivity of the human ear and significantly decreases the weight of sounds with frequencies below $1 \mathrm{kHz}$ and slightly increases the weight of higher frequencies. The $\mathrm{C}$-weighting curve is close to a flat characteristic and is appropriate for measuring the noise emitted by machines and devices.

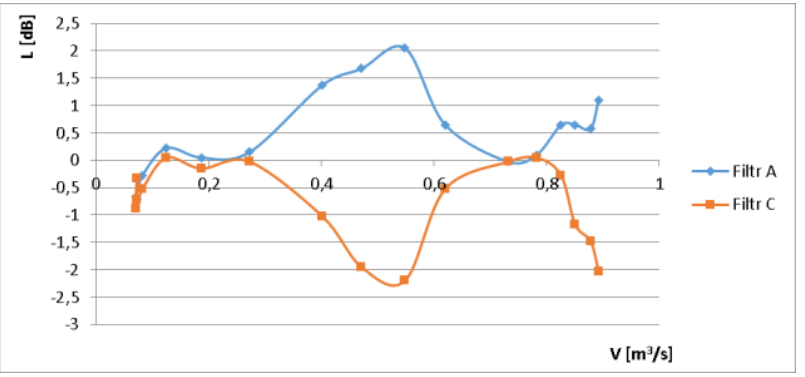

Fig. 8. Noise measurements

These assumptions have been confirmed by the analysis of the samples that were recorded. It was conducted using the MATLAB software. The use of Fourier transform enabled observation of the sound level over the whole scale range (dBFS) for various frequencies. Two areas deserve particular attention. The first of them corresponds to high frequencies for which the values are definitely higher in the case of the impeller with blade slots. The second area is the range of low and medium frequencies. In this case this impeller has higher sound levels.

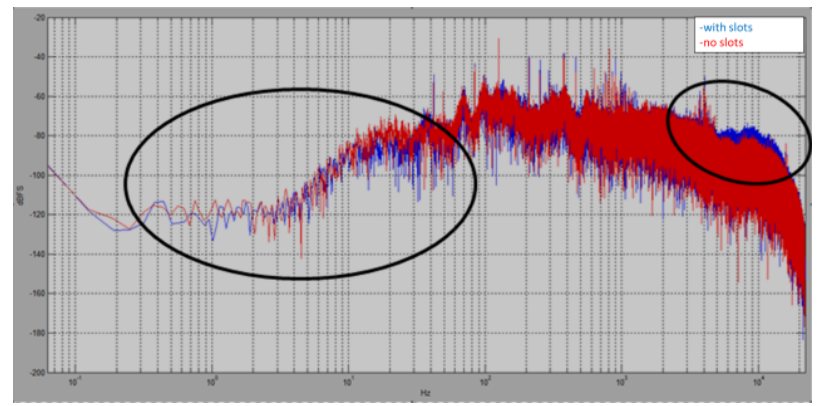

Fig. 9. Spectral analysis of the sound

\section{Summary and conclusions}

Among the many different ways of controlling flow, within the range of rotodynamic machines it is the passive methods that prevail. The key issue affecting the range of operation of blade slots is the shape of the impeller. In the case considered above the blade is flat, and therefore separations for above-optimal flows occur already in the region of the leading edge. The flow of the medium though the apertures does not prevent the occurrence of this phenomenon but only contributes to increasing the losses. For below-optimal flows, the separation phenomenon occurs in the central region of the blade, which means it can be controlled using slots. It also produces a slight increase in total efficiency and pressure. An analysis of the acoustic performance of the fan has shown a positive effect of the blade slots on reducing the noise generated, above all in the range of low sound frequencies. This study is limited to presenting the impact of several configurations on the operating parameters of a particular type of fan. It is proposed that a further analysis should be performed to optimise the arrangement of the apertures and investigate its impact on impellers with forward or backward curved blades.

\section{References}

1. Arakeri J., Shankar P.: Ludwig Prandtl and Boundary Layers in Fluid Flow. Resonance. Journal of Science Education, No. 12 (2000), pp. $48-63$

2. Atik H.: Boundary-layer Separation Control on a Thin Airfoil Using Local Suction. Journal of Fluid Mechanics, Cambridge University Press, No. 535 (2005), pp. 415-443

3. Jesionek K.: Prognozowanie oderwania strumienia i możliwości jego ograniczenia w przepływowych maszynach energetycznych, Wrocław, Oficyna Wydawnicza Politechniki Wrocławskiej (1998)

4. Krzysiak A.: Zastosowanie nowego rodzaju strumieniowych generatorów wirów do sterowania przepływem. Prace Instytutu Lotnictwa, No. 212 (2011)

5. Wursthorn S., Schnerr G.: Numerical Investigations of Cavitation Control in Pumps. ZAMM Journal of applied mathematics and mechanics, No. 80 (2000)

6. Kassim M., Saleh F., Kadhum M.: Experimental and Numerical Investigation of Blades Slots on Rotating Stall Phenomenon in Centrifugal Blower. Universal Journal of Engineering Science, pp. 24-37 (2015)

7. Karanth K. V., Sharma N. Y.: CFD Analysis of a Centrifugal Fan for Performance Enhancement Using Converging Boundary Layer Suction Slots, World Academy of Science, Engineering and Technology, Vol. 60, pp. 381-387 (2009)

8. Fortuna S.: Wentylaotry. Podstawy teoretyczne. Zagadnienia konstrukcyjno-eksploatacyjne i zastosowanie, Kraków, Techwent (1999)

9. Kuczewski S.: Wentylatory promieniowe. Teoria i podstawy projektowania, Warszawa, Wydawnictwa Naukowo-Techniczne (1966)

10. PN-72/M-43120:1972. Wentylatory - Metody pomiaru hałasu

11. PN-EN ISO 5801:2017-12. Wentylatory Badanie właściwości użytkowych z zastosowaniem stanowisk znormalizowanych. 